\title{
DEZ MOTIVOS PARA A INCLUSÃO DE TEMAS DE GEOLOGIA NA EDUCAÇÃO BÁSICA
}

\section{CELSO DAL RÉ CARNEIRO ${ }^{1}$, MARIA CRISTINA MOTTA DE TOLEDO² \& FERNANDO FLÁVIO MARQUES DE ALMEIDA ${ }^{3}$}

\begin{abstract}
TEN REASONS FOR THE INCLUSION OF GEOLOGICAL THEMES IN BASIC EDUCATION Basic Education is privileged to form a responsible and consequent citizenship due to the introduction of a broad environmental concern, amongst other concepts. There are at least ten reasons for the insertion of a geologic culture in this framework. The insertion will widely benefit the Brazilian education, as follows: (1) the Science curricula of basic education is fragmentary and too much superficial. (2) the humanist formation, inherent to the practice of Earth Sciences, should induce solidary and humanist attitudes in the new generations, develop critical thinking and the capacity of observation. Geology allows one to think about the rational use of the technological applications and advances of Science; it supplies (3) a broad vision of the Earth Systems, needed to understand the complex dynamics of the planet. The theoretical body of Geology brings a (4) time perspective of the changes that have affected the planet and living organisms. The particular situation of Geology, the unique science which has experienced a scientific revolution in the $\mathrm{XX}^{\text {th }}$ Century, offers the students an (5) education on the causes of geologic risks and their consequences for the human kind, and allows many examples on (6) participation of Geology in modern discoveries of Science. It introduces the most current discussion of (7) the question of the available resources versus sustainability of life. It also constitutes a (8) preparation and orientation for further studies or critical reflections on the human activities on Earth. More can be learned on the methodological aspects of Science, since Geology favors (9) an education on varied scientific procedures. The Information Society, whose dominant role is felt in all sectors of human activity, constitutes another reason: (10) Geosciences helps to create a planetary perspective. The development of a geologic culture extends beyond the mere domain of the recent advances of Science \& Technology; therefore, it allows to bring the real world into the classroom and, overall, it allows to move the classroom towards the real world. Geology concepts help a search for a more practical and efficient education, since it is supported by an existential reality that will allow people to retain such knowledge through life.
\end{abstract}

\section{Keywords: Education, Geology, Geosciences, classes}

Resumo A Educação Básica é privilegiada para se formar uma cidadania responsável e conseqüente, graças à introdução de preocupações ambientais, ao lado de outros conceitos. Descrevem-se dez razões pelas quais a inserção de cultura geológica beneficiará o ensino brasileiro, obedecendo às diretrizes educacionais atuais: (1) o currículo de Ciências do ensino fundamental é fragmentário e superficial. (2) A formação humanista, inerente ao exercício das Ciências da Terra, deve incutir atitudes solidárias e humanistas nas novas gerações, e desenvolver pensamento crítico e capacidade de observação/indagação. A Geologia permite reflexões sobre o uso racional das aplicações tecnológicas e avanços da Ciência e fornece (3) visão de conjunto do funcionamento do Sistema Terra, necessária para o entendimento da complexa dinâmica do planeta. Traz ainda, em seu corpo teórico, uma (4) perspectiva temporal das mudanças que afetaram nosso planeta e os seres vivos que o povoaram. Como a única ciência que vivenciou uma revolução científica no século XX, a Geologia oferece (5) formação sobre causas dos riscos geológicos e suas consequiências para a humanidade, e proporciona exemplos recentes sobre (6) a participação da Geologia em descobertas modernas da Ciência. Introduz ainda a discussão atualíssima da (7) questão dos recursos disponíveis versus sustentabilidade do planeta, além de constituir (8) preparação e orientação para estudos posteriores ou para a reflexão crítica da atividade humana no planeta. O conhecimento da base metodológica da Geologia favorece (9) formação sobre variados procedimentos científicos. A Sociedade Informática, cujo papel dominante se faz sentir em todos os setores da atividade humana, constitui a décima razão: (10) as Geociências ajudam a formar uma perspectiva planetária. O desenvolvimento de cultura geológica estende-se além do mero domínio dos avanços de Ciência \& Tecnologia, por ser via de mãodupla: permite trazer o mundo real para a sala-de-aula e, sobretudo, permite levar a sala-de-aula para o mundo real. A busca de um ensino mais prático e eficaz, apoiado em realidade vivencial, permitirá que as pessoas contem com essa bagagem ao longo de toda a vida.

Palavras-chave: Educação, Geologia, Geociências, aulas, Educação Básica, níveis de ensino fundamental e médio

INTRODUÇÃO A discussão sobre a necessidade de temas geológicos serem abordados nos atuais níveis de ensino fundamental e médio vem se fortalecendo, com intermitência, no Brasil. Tal conscientização é observada em outros países devido à crescente interação das atividades humanas com a dinâmica do meio natural e ao aumento populacional ocorrido no século XX. Mantida a tendência atual, haverá 10 bilhões de pessoas antes do ano 2050 (Babcock 1994). A complexidade de ambas - as atividades humanas e a dinâmica natural - determinam que as questões de natureza ambiental passem a integrar o corpo de conhecimentos básicos que uma pessoa deveria possuir, para exercer, ao longo de sua vida, aquilo que se entende por cidadania responsável e conseqüente.

Alvarez Suárez et al. (1992b) discutem possível reformulação curricular de bachillerato (idades de 12 a 16 anos) em algumas comunidades autônomas espanholas, apoiada pelo Ministério de Educação e Ciência e apresentam 30 razões favoráveis à inclusão de conteúdos de Geologia na educação secundária obrigatória. O conjunto de razões (sociológicas, epistemológicas e psicopedagógicas), justifica levar os fundamentos de Geologia ao conheci-

I - Instituto de Geociências UNICAMP. Caixa Postal 6152, CEP 13083-970, Fax +55 (19) 3289 1562, Campinas, SP, Brasil. E-mail: cedrec@ige.unicamp.br 2 - Instituto de Geociências USP. Rua do Lago, 652, CEP 05508-080, Fax +55 (11) 3091 4207, São Paulo, SP, Brasil. E-mail: mcristol@usp.br 3 - Professor Catedrático Aposentado pela Escola Politécnica USP. Rua José Varela 57, City Interlagos, CEP 04788-020, São Paulo SP. E-mail: ffma@uol.com.br 
mento dos cidadãos. Pedrinaci (2002) analisa, uma década mais tarde, alguns efeitos da reforma curricular, considerando sete eixos básicos da formação que deveria ser proporcionada aos alunos. Conclui que a reforma não fora bem-sucedida, pois o novo currículo de $1^{\circ}$ [ciclo] de bachillerato constitui mistura de conteúdos de Ciências da Terra desestruturados e mal-selecionados, além de cobrir apenas dois dos sete indicadores utilizados.

Se, na segunda metade do século XX, houve inestimável progresso no conhecimento básico de Geologia, nas escolas persiste um ensino que, quando focaliza temas introdutórios de geologia, "requer a memorização de inúmeras rochas, minerais e fósseis" (Haney 1993). Consequentemente, "milhares de estudantes de áreas não-geológicas", dos quais alguns podem tornar-se futuros políticos (Haney 1993), desconhecem conceitos e aplicações da Geologia que efetivamente atendam às necessidades sociais. A falta de uso leva ao rápido abandono dos termos memorizados.

A cultura geológica é essencial, no âmbito das Geociências, para entendimento de muitos dos temas científicos em cuja pesquisa são investidas enormes somas de recursos e que merecem a dedicação de cientistas de todo o mundo (Sgarbi 2001). No Brasil, praticamente inexiste cultura geológica nos alunos que completam a educação básica (níveis de ensino fundamental e médio) e tentam ingressar na educação superior. Questões simples envolvendo temas geológicos são "filtros" potentes em tal seleção, pela eficácia em eliminar alunos "menos bem preparados".

A maior atenção que vem sendo dada nos EUA para os conteúdos de Geologia em cursos pré-universitários facilita sua assimilação por aqueles que concluem alguns cursos superiores (biólogos, geógrafos, físicos, engenheiros e químicos dentre outros), mas não impede um alto grau de ignorância no público em geral sobre esses temas (Sgarbi 2001). O filme The Core (O Núcleo), que admite ser viável uma viagem ao interior terrestre, é exemplo das fantasias da indústria cinematográfica que focalizam superficial e equivocadamente questões complexas sobre o planeta no qual vivemos. Os chamados meios não-formais de ensino (museus, parques naturais, imprensa e a indústria cultural em geral) exercem papel notável na difusão de conteúdos de Geociências, mas ainda são insuficientes, e podem até ser equivocados, para acomodar a bagagem de conhecimento necessária para uma pessoa de escolaridade mediana se considerar bem-informada e capaz de tomar decisões solidamente apoiadas na ciência moderna.

Pretendemos demonstrar que há bons argumentos para se mudar radicalmente a atual carência de cultura geológica entre as pessoas por meio - e em função - do currículo escolar brasileiro.

\section{MOTIVOS PARA DESENVOLVIMENTO DE CULTURA GE-}

OLÓGICA Apresentam-se a seguir, sinteticamente, dez razões para desenvolvimento de cultura geológica ao longo das diversas etapas da educação básica, com base em exemplos extraídos das diretrizes educacionais em vigor. Coleção mais extensa poderia ser feita, mas pensamos ter destacado os pontos mais relevantes. Analisa-se nos nove primeiros itens a inserção da Geologia na escola básica, para culminar com alguns efeitos da chamada segunda Revolução Industrial, que criou a chamada Sociedade Informática ou do Conhecimento (item 10).

Geociências no Ensino Fundamental Para Campos (1997), o programa de Ciências do ensino fundamental brasileiro é fragmentário. É também muito superficial. Dividido segundo os tópicos ar, água e solo, não permite que o professor "descreva aos seus alunos o mundo em que vivemos, sua origem, evolução e destino"
(Campos 1997). Barbosa (2003) assinala a insuficiente disponibilidade de material didático no ensino fundamental e questiona as razões pelas quais livros didáticos que abordam tais assuntos são elaborados por docentes da área de Biologia ou Geografia. Ainda que o livro didático busque sanar algumas deficiências, persiste a falta de uma visão integrada da Terra e das interações entre seus sistemas.

Noções de Geologia e Geociências dispersam-se no currículo sob vários títulos, faltando uma ordenação capaz de explicar a Terra em conjunto, desde sua constituição, origem e evolução, fenômenos interiores e superficiais, as interações das esferas (oceanos, atmosfera, litosfera, biosfera), e as profundas e diversificadas relações entre meio físico e seres vivos. Os alunos deveriam ser estimulados a compreender processos e mecanismos de evolução do planeta, externos ou internos, e avaliar, em paralelo, os avanços modernos de pesquisa sobre a interação entre tais esferas, para conscientizar-se sobre problemas como os dos recursos naturais não-renováveis e dos atuais níveis de consumo de combustíveis fósseis (Campos 1997).

Geociências na formação humanística A Educação Básica (EB) deve se dar segundo uma perspectiva formativa, que inclua não apenas o domínio dos avanços recentes de Ciência \& Tecnologia (C\&T), mas também formar novas atitudes e valores. Em uma sociedade democrática e aberta, a EB deverá sensibilizar as novas gerações e nelas incutir atitudes solidárias e humanistas mas não se desenvolvem tais atitudes apenas prevendo mais tempo em sala-de-aula para História, Literatura e Língua (Domingo e Sequeiros 1998), mas atendendo-se a alguns aspectos relevantes dessa formação integrada. Esses autores discutem mudanças no currículo espanhol de bachillerato e assinalam contribuições decisivas da Geologia para uma formação humanista, como:

1 - Educação em valores sociais. Muito além da memorização das informações científicas, uma formação em Ciência deve auxiliar o desenvolvimento de valores como tolerância, democracia, respeito a direitos humanos, educação ambiental etc. (Domingo \& Sequeiros 1998).

2 - Pensamento crítico e capacidade de observaçãolindagação. O desenvolvimento dessas capacidades deve habilitar os alunos a situar suas observações no contexto social e a elaborar conclusões e propostas de intervenção responsável na sociedade.

3 - Reflexão sobre o uso racional das aplicações tecnológicas decorrentes dos avanços da Ciência. A importância indiscutível da base tecnológica do mundo moderno não tem levado à reflexão sobre o uso racional da tecnologia e suas implicações sociais: o estudo das relações entre a humanidade e a realidade natural, entre o desenvolvimento tecnológico e a harmonia global do mundo. Para essa finalidade, Domingo \& Sequeiros (1998) destacam a necessidade de um estudo "crítico, aberto e comprometido das disciplinas científicas", entre as quais se inclui a Geologia.

Em uma sociedade cientificamente instruída, há entendimentos e hábitos de pensamento essenciais para todo e qualquer cidadão (AAAS 1989). A simples identificação de aspectos bási$\cos$ da formação a ser proporcionada aos alunos fornece muitos argumentos para inclusão de temas de Geologia na escola básica.

Geologia como visão de conjunto do funcionamento do Sistema Terra Pedrinaci (2002) utiliza sete indicadores para avaliar efeitos de reforma curricular recente na Espanha. A "visão de como a Terra funciona" é o mais relevante, quando se pensa que os cida- 
dãos assim formados viverão toda sua vida em contato com imagens de satélites e outras inovações que aprimoraram a capacidade de observação do planeta, pelo Homem, no século XX.

A missão central da Geologia é entender como funciona o planeta e determinar as causas dos fenômenos. Algumas limitações dessa abordagem favoreceram o nascimento da concepção integradora de Geologia e ciências afins proporcionada pelas $\mathrm{Ci}$ ências da Terra. O entendimento da Terra como um sistema "permite explorar uma visão holística do planeta" (Anguita 1994) e oferece dimensão mais clara - no tocante às mudanças climáticas globais - da "experiência aterrorizante [...] tanto em escala quanto em complexidade" (Lawton 2001) que a humanidade realiza no planeta.

Para Mayer \& Tokuyama (2003), cientistas de diferentes partes do globo "compartilham um único objeto de estudo - a Terra e seu ambiente no espaço - e um método comum de estudo e comunicação - os procedimentos e a linguagem da ciência". A interação envolve abordagem interdisciplinar na qual cientistas de diferentes disciplinas - que incluem as ciências sociais - trabalham em cooperação aplicando seu conhecimento, habilidades e métodos específicos para entender como os sistemas operam, como interagem e de que modo os humanos afetam esses sistemas. Assim, Mayer et al. (1999) assinalam que Ciência do Sistema Terra (Earth Systems Science) constitui um modelo para grande parte da pesquisa realizada atualmente nos EUA, pois oferece aos estudantes uma perspectiva global sobre o funcionamento do planeta.

Perspectiva temporal das mudanças que afetaram o planeta e os seres vivos O conceito de tempo geológico é uma das mais importantes contribuições da Geologia para o pensamento humano (Gould 1987). Diferentes motivos existem para que a EB se aproprie mais intensivamente do mais fundamental conceito geológico: o tempo. Além da aplicação prática do conhecimento sobre a dinâmica terrestre, a história da Terra e da vida é fundamental para se entender a natureza e sua história. Para enfatizar este ponto, Pedrinaci (2002) aproveita a brilhante referência formulada pelo Grupo Terra (Alvarez et al. 1992b):

A Geologia (...) não é a única ciência da natureza.

Nem sequer é a única ciência da Terra, mas é a única que nos conta a história da Terra e da natureza.

Formação sobre riscos geológicos, causas e conseqüências para a humanidade Brusi et al. (2002) relatam conclusões de Simpósio sobre Ensino de Geologia em Girona, Espanha, em julho de 2002, cujo documento final defende a atualidade da inclusão das Geociências no Bachillerato: basta folhear qualquer jornal ou periódico de divulgação para "constatar que duas de cada três notícias de sociedade estão relacionadas com a Biologia ou a Geologia".

As incontáveis situações de risco geológico vividas pela humanidade levaram as Ciências da Terra a incrementar seu papel na pesquisa, tratamento e resolução de problemas complexos de grande interesse social e econômico (Pedrinaci 2002). Em Ciência do Sistema Terra, barreiras disciplinares tradicionais foram derrubadas para propiciar novos campos integrados de pesquisa para o estudo das chamadas "mudanças globais". O enfoque sistêmico de CST favorece currículos de Educação Básica capazes de articular o entendimento dos processos naturais com o das atividades humanas. A idéia de risco geológico possui profundas raízes nessas relações; sua apropriação didática contribuirá significativamente para o entendimento do papel do Homem no funcionamento do planeta.
Participação da Geologia em descobertas modernas da Ciência Sgarbi (2001) resume a contribuição dada pela Geologia para o entendimento de seis temas contemporâneos que denominou "aglutinantes". Os temas foram definidos a partir de pesquisas atuais, relatados em revistas especializadas: a origem das atmosferas, a origem da vida no universo, a Terra como uma bola de neve (snowball Earth), a estocagem geológica de gases no efeito estufa, as extinções de espécies e, finalmente, as mudanças climáticas.

Fronteiras de pesquisa acham-se hoje delineadas em vários desses campos, com avanços capazes de mudar radicalmente a perspectiva de vida das sociedades no futuro. Um exemplo é a possibilidade de se incrementar o armazenamento de carbono em reservatórios naturais - e, consequentemente, alterar a tendência atual ao efeito estufa - mediante estímulo a processos geológicos ativos desde há bilhões de anos. Os horizontes temporais ultrapassam em muito o tempo histórico, compreendido como o tempo social; assim, o entendimento desses fenômenos complexos requer das pessoas em geral, outra vez, um mínimo de conhecimento sobre a dinâmica dos processos atuantes no planeta.

A questão dos recursos disponíveis versus sustentabilidade do planeta A idéia de sustentabilidade da vida humana no planeta tem sido debatida desde o aparecimento do Relatório Bruntland (Bruntland 1987). Chesworth (2002) assinala que a agricultura é um processo geológico, dada a quantidade de materiais terrestres movimentados, que rivalizam com "outros processos superficiais que afetam a biosfera"; o autor indica ainda que não se pode considerar a agricultura atual "mais sustentável do que aquela praticada na antiga Mesopotâmia" (Chesworth 2002), pela incapacidade de deixar o ecossistema "viável e recarregado após cada colheita".

Para Pedrinaci (2002), todos os materiais utilizados pela humanidade são minerais e rochas mais ou menos transformados, com exceção da "madeira, fibra vegetal, lã e couro". Isso justifica o interesse de se conhecer quais são os materiais encontrados, disponibilidade e reservas dos recursos naturais de origem geológica, que, naturalmente, incluem a água doce (Anguita 1994). Conhecimentos técnicos precisos são necessários para determinar os processos de acumulação, dimensionar quantidades, ou até mesmo estimar a duração das reservas disponíveis (Alvarez et al. 1992b). Pedrinaci (2002) conclui que o tema da sustentabilidade do planeta de certo modo vem sendo explorado pela disciplina de Ciências da Terra e do Meio Ambiente, do $2^{\circ}$ [ciclo] de bachillerato.

Preparação e orientação para estudos posteriores ou para reflexão crítica da atividade humana no planeta Conhecimentos técnicos precisos são necessários nas atividades humanas que dependem de se conhecer a Terra ou os materiais terrestres com diferentes objetivos. É requerida certa base geológica, que vai além da idéia de "sustentabilidade", para tratar de temas como ocupação e apropriação do espaço natural, a sua utilização ou a construção sobre ele, o emprego de recursos naturais, sua transformação ou sua conservação e, finalmente, a interação de seres vivos com o meio natural. Tais atividades surgem no dia-a-dia de diversas ocupações profissionais, como os engenheiros, arquitetos, hidrólogos, geógrafos, biólogos, ecólogos etc.

Em Educação, muitas vezes a representação das idéias substitui as idéias em si mesmas (Kay 1991). Já que os alunos ouvem sobre grandes descobertas "em lugar de receberem ajuda para aprender profundamente por si mesmos", a questão ambiental 
passaria a ser palco privilegiado no qual questões mais complexas são superficialmente tocadas. Para existirem decisões sólidas e adequadas sobre problemas ambientais, além da existência de profissionais devidamente habilitados, em uma dada comunidade os cidadãos e os tomadores de decisão (no poder público e empresas) deveriam estar bem instruídos e informados. Carneiro (1996) assinala o baixo domínio de conceitos e temas correlatos à Geologia por planejadores e tomadores de decisão; pondera que o acesso à informação especializada em Geologia é restrito a poucas pessoas e organizações. Como a formação é idêntico "privilégio", conclui que a incipiente difusão das Ciências da Terra facilita desvalorizá-la em relação a outras atividades mais bem divulgadas, o que se reflete no fraco apoio do Poder Público para programas nesse campo da ciência.

Meira (2003) apresenta curioso exemplo do significado das idéias de preservação ou conservação ambientais, ao explorar certo entendimento ditado pelo "senso comum":

“(...) Estamos vivendo num curioso instantâneo de espaçotempo, como todos antes de nós viveram. Mas a percepção da crise de sobrevivência que nosso planeta enfrenta tem criado situações interessantes, magníficas, e, também, ridículas. Uns, destroem sem pensar. Outros, preservam sem pensar. Dia desses, estive numa conversa sobre a "preservação" de um conjunto de dunas, o que era entendido como a estabilização das ditas. Ora, se dunas são coisas móveis por excelência, paralisá-las, por conseguinte, é interferir destrutivamente no meio. Mas o que se queria, de fato, era "preservar" uma beleza natural criada por um conjunto de dunas que haviam chegado até o lugar onde estavam... algo como achar que a foto ou o filme são mais desejáveis, definitivas e melhores do que a realidade, como se o mapa de Borges fosse o mundo nele representado."

A Educação Ambiental pode auxiliar a divulgação de idéias como temporalidade, abrangência, ciclicidade e duração dos processos terrestres, relevantes contribuições dos geólogos ao debate ambiental.

Formação sobre os procedimentos científicos da Geologia Paschoale (1984) assinala que a tarefa básica do geólogo é construir interpretantes que possibilitam, dialeticamente, aumentar o conhecimento sobre a dinâmica do planeta e, progressivamente, ajudam a humanidade a apropriar-se da natureza e transformar o ambiente.

Dois eixos de análise adotados por Pedrinaci (2002) são, até certo ponto, complementares, pois envolvem: (a) formação sobre procedimentos científicos da Geologia, e (b) utilização de conceitos geológicos para tratamento de noções básicas sobre a natureza da Ciência e seus processos de construção. Isso pode levar os alunos a compreender a diversidade desses procedimentos e a importância de sua contribuição na ciência. Há dois aspectos a considerar: a Geologia como ciência experimental e a Geologia como ciência histórica.

A Geologia constitui ciência experimental pois utiliza amplamente os métodos comuns a outras ciências, como observação, medição, análise de dados, classificação, elaboração de hipóteses, definição e controle de variáveis, comparação etc. Sob tais aspectos, o papel formativo da Geologia não difere daqueles que outras ciências podem desempenhar. Entretanto, tal posição é incômoda devido a outros fatores, como o forte componente histórico (Pedrinaci 2002) que impregna a Geologia. Tal singularidade, amplamente debatida (p. ex. Gould 1987), culmina no reconhecimento de outra importante contribuição da Geologia para a ciên- cia, o princípio do Atualismo (Carneiro et al. 1994). Ambos aspectos são, portanto, indissociáveis e devem estar presentes na EB.

Reconhecido o duplo papel formativo da Geologia, como ciência experimental e como ciência histórica, identificam-se as causas de algumas dificuldades comuns dos professores, pois tal amplitude incomoda aqueles menos bem preparados para lidar com o componente histórico.

As Geociências na sociedade informática Schaff(1995) assinala três elementos da revolução técnico-científica que definirá o caminho da humanidade no século que se inicia: a microeletrônica, a microbiologia e a energia nuclear por meio da fusão controlada. Assinala esse autor as profundas modificações econômicas, políticas e culturais da sociedade decorrentes da revolução informática, com destaque para a idéia de "Sociedade Informática", que facilita o entendimento das mudanças aceleradas que já afligem as sociedades. O prenúncio destas é dado pelo que Schaff (1995, p. 27) chamou "exército de pessoas estruturalmente desempregadas": cidadãos que perderam empregos "devido à automação e robotização da produção e dos serviços".

À medida que a ciência passa a se tornar o "mais importante meio de produção" (Schaff 1995), não desaparecerão todas as formas de trabalho, porém algumas tenderão ao abandono, outras serão quantitativamente mais valorizadas, e novos campos serão criados. Se por um lado, para esse autor, tornou-se possível vislumbrar soluções tecnológicas para os principais tormentos do Terceiro Mundo, como a fome, a escassez de água e a desertificação, a sociedade informática vê potencialmente agravar-se o aterrador problema de desemprego estrutural que já assola, por outras razões, os mesmos países do Terceiro Mundo. Prossegue (Schaff 1995, p. 123):

“(...) Dado que, pelo menos no primeiro período, isso [o desemprego estrutural] afetará sobretudo os jovens, o perigo do mal-estar social para essas massas humanas será enorme, mesmo que o Estado se encarregue inteiramente dos custos da sua subsistência. Daí a necessidade de se encontrar para eles novas formas de ocupação que, sendo aceitas pela sociedade, manterão intactos os estímulos hoje ligados ao trabalho remunerado e que servirão como base para a criação de um novo sentido de vida na nova sociedade."

Uma possibilidade sugerida por Schaff (1995) para cuidar da. ocupação da maioria dos cidadãos, em favor da estabilidade de uma sociedade democrática, é a educação permanente (ou continuada), capaz de combinar "uma atividade de verdadeiro estudo com uma atividade de ensino". Tal função seria um dever social, tal como hoje o é a escola obrigatória. Nessa oportunidade notável, a educação continuada poderá aumentar a difusão dos conhecimentos sobre o funcionamento geral do planeta, na medida em que expandirá a participação da sociedade em geral - e não apenas dos estudantes de ensino médio - na retenção e construção de conhecimentos sobre a dinâmica do planeta. Tal envolvimento poderá exceder o contexto das questões ambientais e até mesmo aplicar noções de Ciência do Sistema Terra capazes de orientar mais adequadamente a ação humana. O entendimento da evolução geológica do planeta, desde a escola básica, poderá culminar na formação de uma perspectiva planetária e exigirá visão ampla da posição ocupada pela Terra nos Sistemas mais amplos em que se insere.

GEOCIÊNCIASNOENSINO MÉDIO Toledo (2002) assinala existir no ensino médio brasileiro grande fragmentação do conhe- 
cimento da Terra, uma vez que os conceitos de Geociências dispersam-se em outras disciplinas. De fato, os PCNEM (Parâmetros Curriculares Nacionais de Ensino Médio) consideram Biologia, Física, Química, Geografia, História e Filosofia como "campos do conhecimento que contribuem para o estudo da dinâmica ambiental, possibilitando ao aluno relacionar conceitos aprendidos nessas disciplinas, numa conceituação mais ampla de ecossistema". Tal dispersão é uma clara subordinação a abordagens específicas dessas ciências, sob a ótica que lhes é particular. Em lugar de uma visão integrada, há nítida e improdutiva dissociação (Toledo 2002), pois:

- perde-se de vista a noção de interdependência entre os processos;

- não se apresenta o ciclo natural global;

- desconsidera-se o tempo geológico como fator inerente à sucessão dos processos naturais;

- priva-se os estudantes da oportunidade de utilizar o "laboratório Terra", para compreender e contextualizar os processos físicos e químicos, e ainda a origem e evolução da vida, delineada ao longo do tempo por meio da evolução dos ecossistemas.

A dificuldade dos professores de nível fundamental e médio para ministrar esse conteúdo pode ser explicada por diversas razões, como a deficiente formação acadêmica em Geociências que recebem. Geralmente o primeiro e último contato com esse conteúdo se dá por uma única disciplina de graduação denominada "Introdução às Geociências", "Geologia Geral" ou algo equivalente (Compiani \& Cunha, 1992), como "Ciência do Sistema Terra", disciplina que busca oferecer visão integrada das esferas terrestres e suas interações. Além da formação acadêmica dos professores, outras questões relacionadas a autonomia docente, gestão escolar, currículo, opções ideológicas, políticas, educacionais etc., também devem ser consideradas (Barbosa 2003).

Parâmetros Curriculares Nacionais para o Ensino Médio A Lei de Diretrizes e Bases da Educação Nacional (LDBEN 1996), promulgada em 20 de dezembro de 1996, estabelece como finalidade da educação (Art. $2^{\circ}$ ) "o pleno desenvolvimento do educando, seu preparo para o exercício da cidadania e sua qualificação para o trabalho". Como finalidades do Ensino Médio (Art. $35^{\circ}$ ), estabelece "a consolidação e o aprofundamento dos conhecimentos"; "a preparação básica para o trabalho e a cidadania"; "o aprimoramento como pessoa humana, incluindo a formação ética e o desenvolvimento da autonomia intelectual e do pensamento crítico"; e "a compreensão dos fundamentos científico-tecnológicos dos processos produtivos".

Os Parâmetros Curriculares Nacionais para o Ensino Médio (PCNEM) constituem mecanismo de difusão dos princípios estabelecidos na LDBEN, devendo: (a) contribuir para o processo de elaboração e desenvolvimento dos projetos educativos e (b) exercer função de orientação aos professores para os objetivos desta etapa da Educação Básica, quais sejam:

- dar significado ao conhecimento escolar;

- contextualizar os conhecimentos;

- valorizar a interdisciplinaridade.

Os PCNEM consideram que Biologia, Física, Química, Geografia, História e Filosofia contribuem para o estudo da dinâmica ambiental e possibilitam conceituar ecossistemas, graças à interrelação de conceitos dessas disciplinas. Consideram relevante, na abordagem dos ecossistemas, sua construção no espaço e no tempo e a possibilidade da natureza "absorver impactos e se recompor". Nesse contexto, o estudo da sucessão ecológica permite [...] "relacionar diversidade e estabilidade de ecossistemas" com um equilíbrio dinâmico, aspecto que facilita "avaliar as possibilidades de absorção de impactos pela natureza".

O estudo ordenado das relações entre tais impactos e o equilíbrio da natureza é, em essência, uma das principais missões da Geologia como campo científico.

O conjunto de dispositivos legais dos PCNEM permite articular objetivos para atender à necessidade de se prover os estudantes de uma visão da dinâmica natural, que por sua vez consiste em:

- compreensão dos processos naturais (incluindo condicionantes geológicos) para a origem e desenvolvimento da vida;

- compreensão das interações entre atmosfera, hidrosfera, biosfera e litosfera;

- formação de capacidades para avaliar e julgar as interferências no meio natural e agir dentro das condições de sustentabilidade;

- obtenção de meios para interpretação de fatos naturais e para a percepção evolutiva da vida, do planeta e do cosmos.

Os PCNEM pregam um ensino:

(...) "útil à vida e ao trabalho, no qual as informações, o conhecimento, as competências, as habilidades e os valores desenvolvidos sejam instrumentos reais de percepção, satisfação, interpretação, julgamento, atuação, desenvolvimento pessoal ou de aprendizado permanente".

Existe aí um perfeito entendimento da importância de o aluno compreender o funcionamento do meio natural para tornar-se um cidadão capaz de avaliar e julgar as ações de interferência, ocupação e uso do ambiente e de seus materiais e agir com consciência e responsabilidade nesta questão.

Nos PCNEM a abordagem "interdisciplinar" da Geologia é mais adequadamente descrita pelo adjetivo "fragmentada". Apesar das inúmeras referências a temas geológicos (conceitos, processos, materiais) em Biologia, Química e Física, os educandos geralmente não compreendem as duas últimas como Ciências da Natureza, pois não há referência geológica aos conceitos e fenômenos tratados. Geografia, situada a meio caminho entre Ciências Humanas e Ciências Naturais, inclui múltiplas referências às relações entre espaço físico e sociedade. História, finalmente, referese às diferentes noções de tempo, mas não inclui, como seria de se esperar, a noção de tempo geológico, indispensável para o entendimento da evolução da Natureza.

Tal fragmentação é improdutiva e prejudica o alcance dos objetivos dos PCNEM, pois não dá lugar à idéia da Terra como um sistema complexo no tempo e no espaço, cujos processos, interdependentes e cíclicos, possuem história entrelaçada com a história da vida, modificando continuamente os ecossistemas. Os resultados diretos dessa fragmentação são: equívocos, erros, desatualização, distorção da dinâmica natural e parcialidade da compreensão dos efeitos da ação antrópica sobre a natureza.

Exemplo I-Ciências da Natureza: BIOLOGIA Tomemos um trecho extraído dos PCNEM de Ciências da Natureza:

(...) "o aprendizado disciplinar em Biologia, cujo cenário, a biosfera, é um todo articulado, é inseparável das demais ciências" (...) "a própria compreensão do surgimento e da evolução da vida nas suas diversas formas de manifestação demanda uma compreensão das condições geológicas e ambientais reinantes no planeta primitivo. $\mathrm{O}$ entendimento dos ecossistemas atuais implica um conhecimento da intervenção humana, de caráter social e econômico, assim como dos ciclos de materiais e fluxos de energia"

O cenário da Geologia - a Terra - não é também um todo articulado? Ou será menos importante que a Biosfera? Ou o fato de não haver vida sem planeta não é irrelevante? 
O estudo de certos detalhes biológicos, antes de constituir luxo acadêmico, é justificado: por exemplo, a noção de como operam os mecanismos de codificação genética é justificada com base na necessidade de se entender e emitir julgamento sobre testes de paternidade pela análise de DNA, a clonagem de animais ou a forma como certos vírus produzem imuno-deficiências.

Qual seria a justificativa para privar o aluno, na Educação Básica, de Geologia / Geociências? Sem os conteúdos correspondentes, não se pode emitir julgamento sobre os riscos das atividades de ocupação e uso das paisagens e dos materiais, sobre a viabilidade das soluções propostas para determinados problemas etc. Esses e outros conhecimentos são absolutamente tão importantes quanto a detalhada abordagem de temas biológicos prevista pelos PCNEM.

Exemplo 2 -Ciências da Natureza: QUÍMICA Vejamos agora trechos extraídos dos PCNEM de Química:

(...) [Evitar que as] "transformações químicas do meio (como alterações na atmosfera, hidrosfera, biosfera e litosfera) ocorram por desconhecimento de processos ou por uso inadequado de produtos químicos exige visão integrada da Química, da Física e da Biologia, recorrendo ao instrumental matemático apropriado, mostrando a necessidade das interações entre esses saberes"

O estudo de processos tecnológicos, como a metalurgia, seria tema para aprendizado de conceitos em Química mas também para o entendimento de contexto mais amplo, que inclui a litosfera (em Química? e a Geoquímica?), sob a justificativa de: "estudar fontes naturais de minérios dos quais se extraem os diferentes metais, os processos químicos envolvidos nessas transformações, as implicações sociais, econômicas e ambientais decorrentes da obtenção e do uso desses metais"

O risco inerente a esse procedimento é a formação de uma visão utilitária da Natureza (os recursos estariam aí para servir à sociedade industrial) e não uma visão histórica e dinâmica. Afinal, os recursos são limitados, circunstanciais na dinâmica natural, concentrados por uma sucessão de processos ao longo de milhões ou bilhões de anos; sua retirada, modificação e decorrente produção de resíduos causa desequilíbrios no curso da História Natural, mais extensivos do que a humanidade pode controlar.

A sobrevivência do ser humano, individual e grupal, demanda cada vez mais conhecimento químico para utilização competente e responsável dos materiais, reconhecendo-se as implicações sociais, políticas, econômicas e ambientais desse uso. Enquanto Química ou Física geralmente tratam de materiais isolados do meio natural, Geologia é a ciência que pode integrar as transformações químicas mencionadas e possibilita avaliá-las, junto a outros campos do conhecimento. Surge aqui outro exemplo da importância da interdisciplinaridade.

Exemplo 3-Ciências Humanas: GEOGRAFIA Examinemos agora trechos extraídos dos PCNEM de Geografia:

(...) [A Geografia] "ao buscar compreender as relações econômicas, políticas, sociais e suas práticas nas escalas local, regional, nacional e global, concentra-se e contribui, na realidade, para pensar o espaço enquanto uma totalidade na qual se passam todas as relações cotidianas e se estabelecem as redes sociais nas referidas escalas".

Assim, em que pese a Geografia ter sido redefinida como ciência social, o viés do espaço físico nunca deixou de ter importância fundamental nos seus estudos, sendo a Geografia Física o elo de ligação com a Geologia/Geociências, na medida em que se ocupa do aspecto genético e evolutivo do espaço ocupado pela sociedade. Essa dinâmica, inserida no exercício de mudança freqüente de escala, tanto temporal como espacial, feita em Geologia/ Geociências, permite compreensão mais ampla das relações do ser humano com a Natureza, e representa contribuição significativa aos objetivos da LDBEN.

A Geografia, disciplina que estuda as relações entre a Natureza e o ser humano, tem sido restrita às últimas dezenas de milhares de anos, tempo de existência do Homo sapiens, o que, naturalmente, não dá conta do tempo natural terrestre (tempo geológico, de 4,6 Ga), dimensão necessária para se atingir a compreensão do passado, presente e futuro das relações da Biosfera com o meio físico e das conseqüências das relações da sociedade moderna com a Natureza.

DISCUSSÃO Da exposição precedente, concluímos que permanecem atuais os argumentos de Paschoale et al. (1981) para justificar a inserção de conteúdos de Geologia e Geociências nos níveis de $1^{\circ}$ e $2^{\circ}$ graus (atualmente denominados fundamental e médio):

1) - Contribuição da Geologia para o conhecimento científico da natureza;

2) - Geologia não é Geografia Física, nem aplicação da Química e da Física; constitui sistema de conhecimento abrangente e integrado;

3) - Importância da Geologia no momento histórico vivido pela humanidade, sobretudo pelos problemas de recursos naturais e equilíbrio ambiental;

4) - Geologia como uma área do conhecimento científico bási$\mathrm{co}$

5) - Geologia como perspectiva integradora dos conhecimentos científicos da natureza.

Novas tecnologias, na última metade do século XX, aprimoraram as práticas usuais em Geologia e proporcionaram grande avanço do conhecimento científico. Se o aprendizado de Geologia é uma "alfabetização na linguagem da natureza" (Compiani 1990), não há reflexos da contribuição desse avanço na escola básica, em parte porque os geólogos pouco se interessaram pelas questões de ensino (Toledo 2002).

Recentes descobertas da Ciência, acima citadas, permitem-nos ampliar a lista anterior e acrescentar novos elementos:

6) - Importância da Geologia no momento atual, devido ao aumento da população humana mundial, seus efeitos associados e/ ou eventuais conseqüências: industrial

a) - Forte demanda por água potável e para abastecimento

b) - Forte pressão por energia para as mais diversas finalidades, sociais, industriais e até mesmo militares;

c) - Risco de esgotamento de alguns recursos naturais;

d) - Precauções cabíveis em áreas de reconhecido risco geológico;

e) - Ocupação de espaços antes desabitados, em regiões de risco geológico;

f) - Problemas de contaminação do ar, da água, do solo e acentuação do desequilíbrio ambiental;

7) - Geologia - entendida em um sentido amplo como a Ciência do Sistema Terra - como perspectiva integradora dos conhecimentos científicos da natureza.

8) - Geologia como uma das bases de formação humanista:

a) - sEducação em valores sociais.

b) - Pensamento crítico e capacidade de observação/inda- 
gação.

c) - Reflexão sobre o uso racional das aplicações tecnológicas derivadas dos avanços modernos da Ciência.

9) - Geologia como uma disciplina básica na formação de um cidadão, porque estimula e desenvolve diferentes qualificações e aptidões acadêmicas:

a) - Leitura abrangente e habilidades de compreensão;

b) - Habilidade para escrever, para capacitar os estudantes a efetivamente se comunicarem;

c) - Uso da matemática, lógica e habilidades de raciocínio; alfabetização funcional e operacional e entendimento de estatística; mundo;

d) - A compreensão da história mundial e os negócios no

e) - Conhecimento da geografia mundial;

f) - Conhecimento de línguas estrangeiras.

10) - Geologia como uma das disciplinas aplicadas que contribuem para formar o raciocínio científico, essencial na capacitação de um indivíduo, que precisa possuir:

a) - Fundamentos de conhecimento científico, incluindo ciência aplicada;

b) - Efetivo acesso a informação e habilidades de processa-mento usando tecnologia.

11) - A Geologia permite que o indivíduo se sinta integrante, dependente e agente transformador do ambiente, identificando seus elementos e as interações entre eles. Permite ainda a contribuição efetiva para preservação do ambiente (BRASIL/PCN 1997).

Disciplina Específica ou conteúdos disseminados? Pode-se indagar qual a conveniência ou mesmo a eventual necessidade de se criar uma disciplina específica de Geologia, ao menos no Ensino Médio. É possível tratar conteúdos importantes (como Ciências na 5a série) e enriquecê-los com visão mais "geológica". Um contra-argumento à proposta de se criar disciplina própria acha-se na filosofia dos PCNEM de integrar conteúdos e estimular a interdisciplinaridade, sem compartimentar demasiadamente o conjunto. Programas interdisciplinares acomodariam os conteúdos de forma "transversal", mas podem fragmentá-los, como tem ocorrido em Educação Ambiental. O problema requer especialização e portanto depende da qualidade da capacitação docente. Finalmente, pode persistir a necessidade de disciplina de Geologia/ Geociências mesmo que haja razoável inserção de conteúdos básicos. Contornando-se eventual disputa na grade horária, com outras disciplinas, tal inserção pode trazer grandes vantagens conceituais, que devem ser mais bem avaliadas.

O planeta Terra na sala-de-aula A proposta de fundo da presente comunicação é discutir amplamente o problema de se trazer, cada vez mais, o mundo real para a sala-de-aula. Inúmeros argumentos existem para demonstrar que conteúdos de Geologia facilitam essa tarefa, mas há ainda um outro lado da questão: o problema, ainda maior, de levar a sala-de-aula para o mundo real, missão que a Geologia pode desempenhar com maior eficiência do que qualquer outra disciplina da Educação Básica.

Conteúdos de Geociências podem acentuar o sentimento de que o indivíduo pertence ao lugar onde vive, por meio de um diálogo entre pesquisadores e sociedade. Dentre os exemplos disponíveis, citamos o estudo da paisagem local proposto por Lacreu \& Sosa (2000), ou o modelo denominado geotopos, de Piacenti \& Giusti (2000). Este último alia um viés cultural-ambiental que é aproveitado no Projeto Geo-Escola (Carneiro \& Barbosa 2002a, 2002b). O ensino italiano de Ciências da Terra permanece à margem do ensino científico, sendo pouco explorado nas escolas. Em geotopos, acordos entre universidades e órgãos governamentais e de ensino permitem explorar o conceito de geoconservação, na proteção a áreas de valor especial para a compreensão da História da Terra. Levantamentos bibliográficos e consultas a especialistas e instituições possibilitam definir os geotopos de uma dada região e determinar suas características, riscos e desafios. Realizase a oferta cultural do patrimônio geológico local, graças à compilação da informação geológica disponível e sua divulgação às escolas e à sociedade.

A identificação entre o indivíduo e a história geológica de um lugar (Piacente \& Giusti 2000) expande o significado das informações geológicas, caso seja possível torná-las acessíveis às pessoas. Embora os indivíduos pudessem não sentir, talvez, qualquer interesse prévio por Geologia, a conseqüência seria "um avanço na noção de cidadania e respeito ambiental" (Barbosa 2003).

CONCLUSÕES O conhecimento de Geologia proporciona compreensão mínima do funcionamento do planeta e lança as bases do efetivo exercício da cidadania. Para atingir os objetivos pretendidos de formar cidadãos conscientes, capazes de avaliar e julgar as atividades humanas que envolvem a ocupação e o uso do ambiente e dos materiais naturais, é necessária a introdução de Geologia/Geociências como ciência integradora da Física e da Química e que inclui muitos aspectos biológicos, não como fragmentos, tal como é sugerido nos PCNEM, mas como um todo íntegro.

Os conteúdos geológicos, com seus ramos físicos, químicos e biológicos, podem ser tratados em uma organização interdisciplinar, agrupados, a critério da escola, em projetos ou programas que superem a separação atual entre as diversas disciplinas de Ciências da Natureza, incluindo a Geografia Física. Isto deve ser feito sob a coordenação de pessoal especificamente preparado, uma vez que professores de Ciências, Biologia e Geografia habilitados para esta tarefa são raros. Além da inserção de Geologia/ Geociências por inteiro na formação dos futuros professores, é urgente atualizar todo o professorado que lida com as Ciências Naturais e com a Geografia, para que não deixem de apresentar os tópicos de Geologia/Geociências quando for o caso, e que o façam sem fragmentação, com exatidão e dentro da visão moderna das Ciências da Terra.

Com a Geologia ocupando posições periféricas no currículo da escola básica, a população está sendo privada de conhecimento elementar e essencial. Sob a visão integradora proporcionada pela Ciência do Sistema Terra, à lista de dez motivos para inserção de cultura geológica na Educação Básica, da qual partimos, acrescentamos dois novos relevantes argumentos: trazer o mundo real para a sala-de-aula, e sua recíproca, levar a sala-de-aula para o mundo real. Apresentou-se, pois, uma dúzia de motivos para ilustrar modos pelos quais o acesso à informação geológica decodificada aproximará a população de conceitos de valor inestimável para que as pessoas se sintam parte do patrimônio local onde vivem. Isso pode receber estímulos e contribuições da Geologia, talvez mais intensos que outras disciplinas tradicionais: uma bagagem que acompanhará toda a vida dos participantes.

Agradecimentos Ao Conselho Nacional de Desenvolvimento Científico e Tecnológico $(\mathrm{CNPq})$ por bolsa de produtividade em pesquisa concedida (MCMT, processo 303796/86-3) e aos revisores da $R B G$ pelas sugestões ao manuscrito. 


\section{Referências}

Alvarez Suárez R., Berjillos Ruiz P., Garcia de La Torre E., Melero Vara J., Pedrinaci Rodriguez E., Sequeiros Sanromán L. 1992a. La investigación educativa en ciencias de la Tierra y la didactica de la Geología: unas relaciones necesarias. In: Simposio Enseñanza de la Geología, 7, Santiago de Compostela, 1992. Actas... Santiago de Compostela: AEPECT, p. 231-240.

Alvarez Suárez R., Berjillos Ruiz P., Garcia de La Torre E., Melero Vara J., Pedrinaci Rodriguez E., Sequeiros Sanromán L. 1992b. Treinta razones para aprender más Geología en la educación secundaria. In: Simposio Enseñanza de la Geología, 7, Santiago de Compostela, 1992. Actas... Santiago de Compostela: AEPECT, p. 231-240.

American Association for the Advancement of Science. 1989. Science for all Americans. Washington, D. C.: AAAS.

Anguita Virela F. 1994. Geología, ciencias de la Tierra, ciencias de la naturaleza: paisaje de un aprendizaje global. Enseñanza de las Ciencias. 12(1):15-21.

Babcock E.A. 1994. Geoscience in a changing society. Episodes, 17(4):101-105.

Barbosa R. 2003. Projeto Geo-Escola: recursos computacionais de apoio ao ensino de geociências nos níveis fundamental e médio. Dissertação de Mestrado, Instituto de Geociências, Universidade Estadual de Campinas. 105p. (CD-ROM incluso).

Brasil. Ministério da Educação. Secretaria de Educação Média e Tecnológica. 1999. Parâmetros Curriculares Nacionais: Ensino Médio. Brasília: Ministério da Educação. 1999. 364 p.

Bruntland G. (ed.). 1987. Our Common Future: The World Commission on Environment and Development, Oxford: Oxford Univ. Press.

Brusi D., Vehí M., Cañigueral M. 2002. Informe del XII Simposio sobre Enseñanza de la Geología. Girona, 8 al 13 de julio de 2002. Rev. Enseñanza de las Ciencias de la Tierra. 10(2):111-124.

Campos D.A. 1997. O ensino das ciências da Terra. In: Simpósio a Importância da Ciência para o Desenvolvimento Nacional, 1, São Paulo. Documentos... São Paulo: Acad. Bras. Ciências. p. 39-46. (1". sessão, Educação).

Carneiro C.D.R. 1996. A informação geológica e o ambiente: bases para uma sociedade sustentável. A Terra em Revista, II(2):12-18.

Carneiro C.D.R. \& Barbosa R. 2002a. Demandas de conocimiento de geociencias por profesores de Ciencias y Geografia: el ejemplo de Jundiaí-Atibaia, São Paulo, Brasil. In: Simp. Enseñanza de la Geología, 12, Girona, 2002. Actas... Girona: AEPECT. (Documentos de Trabajo, p. 47-57).

Carneiro C.D.R. \& Barbosa R. 2002b. Geo-Escola: apoio em temas geocientíficos para docentes de Ciências e Geografia no nível fundamental em Jundiaí-Atibaia, SP. In: Congr. Bras. Geol., 41, João Pessoa, 2002. Resumos... João Pessoa, SBG. (Painel, 19-2).

Carneiro C.D.R., Brito-Neves B.B. de, Amaral I.A. do, Bistrichi C.A. 1994. O Atualismo como princípio metodológico em Tectônica. Bol. Geoc. Petrobrás. 8(2/4):275-293.

Chesworth W. 2002. Sustainability and the end of History. Geotimes, 47(10):5 e 52.

Compiani M. 1990. A Geologia pra que te quero no ensino de ciências. Educação e Sociedade, (36):100-117

Compiani M \& Cunha C.A.L.S. 1992. O ensino de Geociências nos 3 graus de escolaridade - um panorama do Brasil. In: Congr. Geol. de España, 3 y Congr: Latinoamericano de Geol., 8. Salamanca, 1992, tomo I, pp. 324-352.

Domingo, M. \& Sequeiros, L. 1998. La extinción de la Geología en España: alerta roja. Rev. de la Enseñanza de las Ciencias de la Tierra. 6(3):206-210.

Gould S.J. 1987. Seta do tempo ciclo do tempo. São Paulo: Cia. das Letras, 221p.

Haney D.C. 1993. Wake up Geologists! Geotimes, Feb. 1993, 38(2):6.

Kay A. 1996. Computers, network and education. Scientific American, special issue The Computer in the 21st Century, p. 148-155. (reimpresso da edição Sci. Am. de setembro de 1991).

Lacreu H. \& Sosa G. del R. 2000. The history of the landscape that surrounds my city. San Luis, Argentina. (poster avulso distribuído na Intern. Conf. on Geosc. Education, 3, Sidney, Austrália, 2000).

Lawton J. 2001. A nova Ciência do Sistema Terra. Jornal da Ciência, SBPC. XV(462): 12. (6 de julho de 2001)

Lei de Diretrizes e Bases da Educação Nacional (LDBEN). 1996. Lei de diretrizes e bases da Educação Nacional. Brasília: Congresso Nacional. Pub DOFC 23/12/1996, p. 027833, Col. 1, Diário Oficial da União. (Lei Darcy Ribeiro, LEI N ${ }^{\circ} 9.394$ de 20 de dezembro de 1996).

Mayer V.J., Fortner R., Kumano Y. 1999. Reforming the representation of science in pre-college curriculum. Columbus, Ohio. Journal of Curriculum and Supervision (submetido em 17 de fevereiro de 1999, comunicação pessoal dos autores)

Mayer V.J. \& Tokuyama A. 2003. Evolution of global science literacy as a curriculum construct. In: V. Mayer 2002. Global Science Literacy. Amsterdam: Klüwer/The Ohio State Univ. p. 3-24. (v. 2, chapter 1).

Meira S.L. 2003. Um mundo feito (quase completamente) de software. Ciência e Cultura, 55(2):24-28.

Paschoale C. 1984. Alice no país da Geologia e o que ela encontrou lá. In: Congr. Bras. Geol., 33, Rio de Janeiro, 1984. Anais... Rio de Janeiro: SBG. v. 5, p. 242-249.

Paschoale C., Freitas H.C.L. de, Fracalanza H., Amaral I.A. do, Tessler M.G. 1981. A geologia e a escola de $1^{\circ}$. e $2^{\circ}$. graus. In: SBG, Simp. Nac. Ensino de Geologia no Brasil, 1, 1981, Belo Horizonte. Teses... Belo Horizonte, 1:157-167.

Pedrinaci E. 2002. La Geología en el bachillerato: un análisis del nuevo curriculum. Rev. Enseñanza de las Ciencias de la Tierra. 10(2):125-133.

Piacente S. \& Giusti C. Geotopos una oportunidad para la difusion y valoracion de la cultura geologica regional. In: Simposio Enseñanza de la Geología, 10, Santander, 2000. Actas... Santander: AEPECT. (Documentos, p. 134-137).

Schaff A. 1995. A Sociedade Informática: as conseqüências sociais da segunda revolução industrial. 4 ed. São Paulo: Ed. UNESP / Brasiliense. 1995. 157p.

Sgarbi G.N.C. 2001. Geologia Introdutória: base para o novo conhecimento. Rev. Ci. Humanas, 1(2):153-162.

Toledo M.C.M. 2002. Geologia/Geociências no Ensino. In: Seminário Nacional sobre Cursos de Geologia, 1, Universidade Estadual de Campinas. (Apres. oral).

Manuscrito A-1439

Recebido em 02 de junho de 2003

Revisão dos autores em 30 de maio de 2004 Révisão aceita em 15 de junho de 2004 